\title{
PRODUÇÃO E FUNCIONALIZAÇÃO DE SUPORTE DE PARAFINA PARA IMOBILIZAÇÃO ENZIMÁTICA
}

\author{
Production and functionalization of paraffin support for enzymatic \\ immobilization
}

\begin{abstract}
Ana Paula Dariff'; Carolina Elisa Demaman Oro ${ }^{1}$; Tiago dos Santos Gonçalves ${ }^{1,2}$;
Andressa Franco Denti ${ }^{1}$; Bethina Pascuetti Tres ${ }^{1}$; Rogério Marcos Dallago ${ }^{1}$; Marcelo Luis Mignoni ${ }^{1, *}$

${ }^{1}$ Departamento de Engenharia de Alimentos e Engenharia Química - Universidade Regional Integrada do Alto Uruguai e das Missões (URI), Erechim, RS.

${ }^{2}$ Departamento de Engenharia de Alimentos, IFC - Instituto Federal Catarinense, Concórdia, SC.

*E-mail:mignoni@uricer.edu.br
\end{abstract}

Data do recebimento: 23/02/2021 - Data do aceite: 16/06/2021

RESUMO: A produção e funcionalização de um suporte de parafina para ligação covalente, reduzindo e simplificando as metodologias de produção de suportes foi o objetivo principal do presente estudo. A ligação covalente fornece uma melhor estabilidade e um bom número de reciclos para a enzima. Dessa forma, foi empregada a parafina como base do suporte, juntamente com os aditivos corante anilina e/ou carvão ativado. O glutaraldeído foi utilizado para a funcionalização do suporte. A enzima estudada foi uma pectinase comercial (Pectinex ${ }^{\circledR}$ Smash XXL), sendo o ancoramento realizado em pH 10. Como resposta, avaliou-se o rendimento, cinética, reusos, aspectos físicos e o teste de Fehling para comprovação da eficiência do processo. O rendimento, para todas as condições testadas, foi de aproximadamente $50 \%$. Observou-se que o suporte apresentou duas faces distintas, devido à metodologia empregada para a síntese do suporte. Além disso, os imobilizados apresentaram 20 ciclos de reuso enzimático, mantendo a estabilidade em aproximadamente 100\%, o que comprova a eficiência do processo proposto.

Palavras-chave: Parafina. Ligação Covalente. Pectinase.

ABSTRACT: Production and functionalization of a paraffin support for covalent bonding, reducing and simplifying support production methodologies 
was the main objective of the present study. The covalent bond provides better stability and a good number of recycles for the enzyme. Thus, paraffin was used as the support base, together with the additives aniline dye and / or activated carbon. Glutaraldehyde was used for the functionalization of the support. The enzyme studied was a commercial pectinase (Pectinex ${ }^{\circledR}$ Smash XXL), and the anchoring was carried out at $\mathrm{pH}$ 10. In response, yield, kinetics, reuses, physical aspects and Fehling test were evaluated to prove the efficiency of the process. The yield, for all conditions tested, was approximately $50 \%$. It was observed that the support had two different faces, due to the methodology used for the synthesis of the support. In addition, the fixed assets presented 20 cycles of enzymatic reuse maintaining stability at approximately $100 \%$, which proves the efficiency of the proposed process.

Keywords: Paraffin. Covalent bond. Pectinase.

\section{Introdução}

As enzimas apresentam várias propriedades que as tornam atrativas como catalisadores para biotransformações. Atualmente, cerca de 6.000 enzimas são catalogadas e destas, cerca de 200 são utilizadas em nível industrial, entre estas salientam-se as aplicações de amilases, celulases, b-galactosidases, proteases, lipases, pectinases, amiloglucosidases e pullanases, glicoses, oxidases e xilanases (BADGUJAR; DHAKE; BHANAGE, 2013; GONÇALVES, 2018).

A técnica de imobilização enzimática tem grande importância por permitir a reutilização de biocatalisadores, além de viabilizar uma fácil e eficiente separação destas moléculas do meio reacional. O principal interesse em imobilizar uma enzima é obter um biocatalisador com atividade e estabilidade que não sejam afetadas durante o processo, em comparação à sua forma livre (FICANHA et al., 2020, 2021; GONÇALVES, 2018). Imobilizações podem ocorrer por diversas formas. Usualmente, as técnicas empregadas para imobilizar enzimas em suportes sólidos são baseadas em mecanismos físicos e quími- cos, podendo ocorrer por adsorção (ALMEIDA et al., 2017), ligação da enzima em um material insolúvel (GIRELLI; SALVAGNI; TAROLA, 2012), emprego de um reagente multifuncional através de ligações cruzadas (CHEN et al., 2017), emprego de aditivos (Ficanha et al., 2021), entre outras técnicas.

$\mathrm{Na}$ imobilização por ligação covalente, normalmente a interação da enzima com o suporte se dá mediante ligação covalente entre grupos aldeídos (-CHO) do suporte com os grupos aminas $\left(-\mathrm{NH}_{2}\right)$ terminais das enzimas (BABAKI et al., 2015)lipases from Candida antarctica (CALB). Esse tipo de imobilização da enzima com o suporte apresenta elevada estabilidade química, minimiza perdas da enzima por lixiviação, e permite um maior número de reciclos. Além disso, a etapa de imobilização pode ser conduzida em temperaturas controladas, normalmente temperatura ambiente, evitando possíveis inativações térmicas (MATEO et al., 2007).

Na imobilização por ligação covalente os átomos são ligados por meio da partilha de pares de elétrons. Estas ligações são formadas entre a enzima e o material utilizado como suporte, ocorrendo através dos aminoácidos de cadeia lateral, como histidina, lisina, arginina, cisteína ou ácido aspártico e glutâmico 
(ALMEIDA et al., 2017). Geralmente, a imobilização covalente de enzimas é realizada em três etapas sucessivas: a ativação inicial do suporte, seguido por modificação do suporte ativado e, finalmente, ligação da enzima com o suporte (BABAKI et al., 2015)lipases from Candida antarctica (CALB). As principais reações de ativação em suportes são realizadas utilizando-se agentes bifuncionais, como por exemplo epicloridrina, glicidol, glioxal, diisocianato de hexametileno, diisocianato de tolueno e glutaraldeído (ADRIANO et al., 2008; GONÇALVES, 2018; RODRIGUES et al., 2008).

O glutaraldeído é um dos reagentes mais empregados na ativação de suportes e/ou como braço espaçador (BARBOSA et al., 2012; CHAUBEY et al., 2009). Nesse caso, a molécula de glutaraldeído reage com o suporte e a enzima, e estas são imobilizadas covalentemente no suporte por reação com seus grupos aminos $\left(\alpha-\mathrm{NH}_{2}\right.$ da cadeia terminal, $\varepsilon-\mathrm{NH}_{2}$ da lisina e/ou $\mathrm{NH}_{2}$ proveniente de aminação química), que se ligam aos grupos aldeídos do suporte, formando as bases de Schiff.

Uma das grandes questões do processo de imobilização é a escolha do suporte. Neste sentido, prioriza-se a busca por um suporte de imobilização enzimática reaproveitável e de baixo custo, respondendo às necessidades do mercado e às vantagens da utilização dos mesmos em relação ao potencial de suas aplicações.

Não é de conhecimento dos autores trabalhos relatando a imobilização enzimática covalente em parafina funcionalizada. $\mathrm{O}$ único trabalho mais próximo é o de Pithawala, Mishra e Bahadur, (2010) que relata a imobilização da enzima urease por incorporação em pano de musselina, impregnado com cera de parafina. As parafinas são, essencialmente, uma mistura de longas cadeias de hidrocarbonetos (alifáticos saturados) com carbonos que vão do $\mathrm{C} 15$ ao $\mathrm{C} 75$, mantidas por forças de dipolos induzidos. Podem ser usadas como material de mudança de fase devido ao seu alto calor latente, baixo custo e pequena alteração no volume de fusão, sendo as propriedades físicas e químicas adequadas (KAHWAJI et al., 2018). A parafina é um derivado do petróleo conhecido por sua alta pureza, comumente encontrada com aparência de cera sólida branca, sem odor, sem gosto, com ponto de fusão típico entre $58{ }^{\circ} \mathrm{C}$ e $62{ }^{\circ} \mathrm{C}$, e insolúvel em água (GANGOLLI, 1999).

Tendo em vista a escassez de relatos na literatura sobre a imobilização enzimática covalente em parafina, o objetivo do presente trabalho baseou-se em uma proposta de imobilização covalente de enzimas pectinolíticas, utilizando como suporte parafina funcionalizada com carvão ativado e/ou corante, buscando avaliar a potencialidade do suporte na imobilização, reduzindo e simplificando as metodologias de produção de suportes e oferecendo uma melhor estabilidade e maior número de reciclos para a enzima.

\section{Material e Métodos}

Os experimentos foram realizados nas instalações da Universidade Regional e Integrada do Alto Uruguai e das Missões (URI). No presente trabalho, o método de ligação covalente foi empregado na imobilização da Pectinex® Smash XXL, utilizando como suporte a parafina com funcionalização in situ empregando o glutaraldeído como agente de ligação entre enzima e o suporte.

Dessa forma, tem-se uma etapa a menos no processo de imobilização da pectinase, que ocorre normalmente com a produção do suporte e, posteriormente, a funcionalização do mesmo com grupos funcionais livres (aldeídos neste caso), para realizarem a ligação covalente com grupos amina desprotonados da enzima, produzindo uma imina, mais co- 
nhecida por base de Schiff. Portanto, ênfase será dada ao suporte utilizado no desenvolvimento deste estudo, a parafina.

\section{Materiais}

Os testes de imobilização enzimática em suporte de parafina foram conduzidos baseados no preceito da ligação covalente entre o suporte e a enzima. Para a base do suporte foi escolhida a parafina, a qual foi obtida no comércio local. O corante anilina e o carvão ativado também foram obtidos no comércio local. O glutaraldeído 50\% (Vetec $\left.{ }^{\circledR}\right)$ e a solução tampão de amônia (pH 10) foram previamente preparadas utilizando os reagentes de grau analítico do laboratório da URI Erechim.

A enzima utilizada no presente estudo foi a Pectinex ${ }^{\circledR}$ Smash XXL, gentilmente cedida pela Novozymes Latin, America Ltda, onde foi mensurada a atividade para a exo-poligalacturonase (PG). A escolha da enzima pectinolítica foi devido às características do suporte, o qual não é solúvel e não interage com os reagentes da medida de atividade para a PG. Quando testado para imobilização com lipase, o suporte solubilizou no ácido oleico (substrato), o que não é desejável.

\section{Síntese do suporte}

Para a síntese do suporte, $10 \mathrm{~g}$ de parafina foram adicionadas a um béquer e submetidas ao aquecimento com auxílio de uma placa de aquecimento, até atingir o completo derretimento da mesma. Após, adicionou-se o corante anilina $(0,1 \% \mathrm{~m} / \mathrm{m})$ e/ou o carvão ativado $(1 \% \mathrm{~m} / \mathrm{m})$, os quais ficam adsorvidos na parafina com o intuito de fornecer terminais $\mathrm{NH}_{2}$ (parte polar) para realizar ligação com o glutaraldeído, o qual posteriormente irá reagir com o grupo amino livre do aminoácido da enzima e, assim, realizar a ligação covalente entre a enzima e o suporte. Como resposta, acompanhou-se o aspecto físico da mistura (se houve ou não solubilidade), onde a homogeneização com bastão de vidro só era cessada após a obtenção de uma solução homogênea. A fim de comparação, realizou-se o mesmo procedimento de obtenção do suporte apenas com a parafina pura (branco).

Após a obtenção da solução homogênea, a mesma foi vertida em um béquer com água fria para solidificação. Após decorridos alguns minutos, o suporte era retirado da água, seco com papel toalha e quebrado manualmente em pequenos pedaços (Figura 1), para que os poros não fossem fechados nas laterais, como acontecia ao cortar com estilete ou faca. Notaram-se duas superfícies distintas no suporte, em todas as condições testadas, sendo elas a superfície que ficava em contato com o ar e a superfície que ficava em contato com a água.

Figura 1 - Suporte de imobilização em parafina. Em (a) a superfície que ficou em contato com o ar, em (b) a superfície que ficou em contato com a água e em (c) o suporte após quebra manual
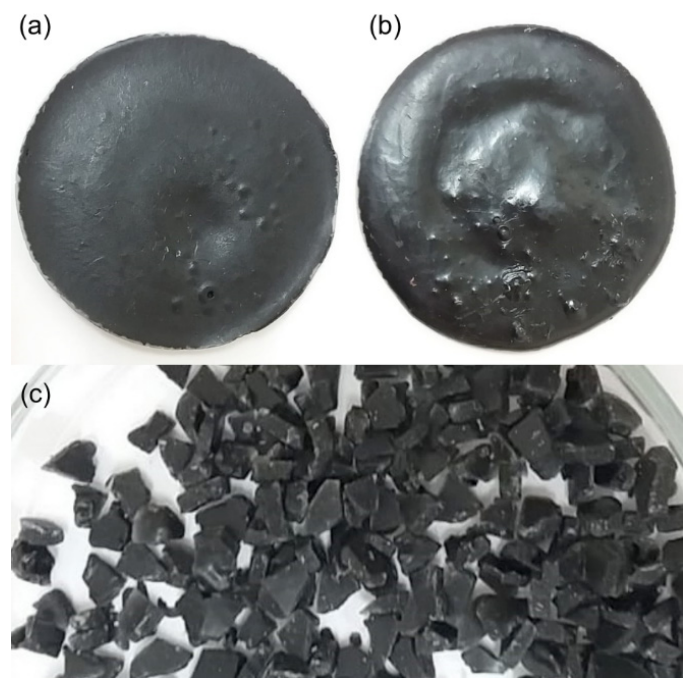


\section{Funcionalização do suporte com glutaraldeído}

Para a funcionalização dos suportes, utilizou-se uma solução de glutaraldeído $50 \%$, em tampão $\mathrm{pH} 10$, a fim de se obter uma base conjugada de Schiff. Para cada teste de funcionalização adicionou-se, aproximadamente, $10 \mathrm{~g}$ de suporte em um erlenmeyer contendo $15 \mathrm{~mL}$ de solução tampão ( $\mathrm{pH} 10), 35 \mathrm{~mL}$ de água destilada e $6 \mathrm{~mL}$ de glutaraldeído (50\%). A mistura ficou por $1 \mathrm{~h} 30 \mathrm{~min}$ em shaker, a $20^{\circ} \mathrm{C}$, com agitação a $200 \mathrm{rpm}$. Após, filtrou-se o suporte com papel filtro e o mesmo foi lavado com água destilada para a remoção do excesso de tampão e glutaraldeído. O suporte foi deixado em temperatura ambiente por 6 horas antes da etapa de imobilização. O mesmo procedimento foi realizado para o suporte contendo apenas parafina (branco).

\section{Imobilização enzimática em suporte de parafina funcionalizado com glutaraldeído}

Após a síntese e funcionalização do suporte de parafina foi realizada a imobilização enzimática utilizando uma enzima pectinolítica. Para a imobilização, utilizou-se 1,5 $\mathrm{g}$ de suporte, o qual foi adicionado em um erlenmeyer contendo $15 \mathrm{~mL}$ de solução tampão (pH 10), $35 \mathrm{~mL}$ de água destilada e $2 \mathrm{~mL}$ de extrato enzimático. A solução ficou por $1 \mathrm{~h} 30 \mathrm{~min}$ em shaker a $20^{\circ} \mathrm{C}$, com agitação a $200 \mathrm{rpm}$. Após, filtrou-se o suporte com papel filtro e o mesmo foi lavado com água destilada para a remoção do excesso da solução, contendo tampão e extrato enzimático. $\mathrm{O}$ suporte foi deixado em temperatura ambiente até a realização dos testes de atividade enzimática.

\section{Atividade de exo-poligalacturonase (PG)}

A atividade de $P G$ da pectinase comercial foi estimada pela quantificação do ácido ga- lacturônico produzido na reação de hidrólise da pectina cítrica, utilizando o método do ácido 3,5 dinitrosalićlíco descrito por Miller (1959) e uma curva de calibração estabelecida com ácido $\alpha$-D-galacturônico (massa molecular 212,6 gmol) como açúcar redutor e o reagente DNS (ácido 3,5 dinitrosalicílico).

Um volume de $500 \mu \mathrm{L}$ de substrato $(0,5$ $\% \mathrm{~m} / \mathrm{v}$ em tampão acetato de sódio $100 \mathrm{mM}$; $\mathrm{pH} 4,5$ ) foi incubado a $37^{\circ} \mathrm{C}$, por 15 minutos, para a estabilização de temperatura. A seguir, $500 \mu \mathrm{L}$ da solução de pectinase foram adicionados ao substrato e a reação foi incubada a $37^{\circ} \mathrm{C}$, por 5 minutos. Posteriormente, foram adicionados $1000 \mu \mathrm{L}$ do reagente DNS. Para a formação da cor, a mistura foi aquecida em banho maria a $100^{\circ} \mathrm{C}$, por 8 minutos, resfriada em banho de gelo. Após foram adicionados $8 \mathrm{~mL}$ de solução de tartarato duplo de sódio potássio $(50 \mathrm{mM})$ para a estabilização da cor, e, finalmente, as absorbâncias das amostras foram medidas em um espectrofotômetro (Beckman Coutler, modelo DU640) a 540 nm contra o branco, o qual foi preparado da mesma forma como descrito anteriormente, com a diferença que o volume de enzima foi substituído por água destilada.

Uma unidade de atividade pectinolítica foi definida como a quantidade de ácido galacturônico gerada por minuto $(\mathrm{U}=\mu \mathrm{mol}$. $\mathrm{min}^{-1}$ ) por grama de imobilizado (U/g) ou $\mathrm{mL}$ de extrato enzimático $(\mathrm{U} / \mathrm{mL})$ sob as condições estudadas.

\section{Estudo cinético do tempo ótimo de imobilização}

$\mathrm{O}$ estudo cinético foi conduzido com o objetivo de determinar o melhor tempo de reação correspondente aos maiores valores de atividade pectinolítica para a enzima imobilizada em suporte de parafina com os diferentes coadjuvantes. As amostras dos suportes imobilizados e da parafina pura $(0,5 \mathrm{~g})$ foram incubadas em uma solução 
contendo 15 mL de solução tampão (pH 10), $35 \mathrm{~mL}$ de água destilada e $2 \mathrm{~mL}$ de enzima. Uma alíquota da solução foi retirada em 5 , $10,15,30,60,90,120,180$ e 210 minutos de reação em shaker a $20^{\circ} \mathrm{C}$ com agitação a 200 rpm. Posteriormente, foi dosada a atividade enzimática como descrito anteriormente.

\section{Rendimento}

O rendimento foi calculado considerando a atividade total oferecida (Uo) no extrato enzimático (a qual considera a atividade do extrato e o volume empregado) e a atividade total presente no imobilizado (Ui), a qual é calculada considerando a atividade do imobilizado e a massa produzida, de acordo com a Equação 1.

$$
R(\%)=\frac{U i}{U o} \times 100
$$

\section{Estabilidade operacional (reciclos)}

A reutilização da pectinase imobilizada nos suportes de parafina foi determinada empregando uma quantidade definida do derivado imobilizado, em sucessivos ciclos, em batelada, durante a hidrólise da pectina cítrica $(0,5 \% \mathrm{~m} / \mathrm{v}, \mathrm{pH} 4,5)$ a $37^{\circ} \mathrm{C}$, por 5 minutos, conforme a atividade de exo-poligalacturonase descrita anteriormente. Após cada batelada, as amostras foram removidas do meio reacional, lavadas com água destilada e adicionadas em uma nova solução de pectina cítrica. A atividade do primeiro ciclo foi considerada como $100 \%$. A eficiência do reuso foi calculada conforme apresentado na Equação 2.

Reciclo $(\%)=\frac{\text { Atividade pectinolítica no ciclo } n}{\text { Atividade pectinolítica no ciclo } 1} \times 100$

\section{Determinação da estrutura dos suportes}

A estrutura dos diferentes suportes com e sem funcionalização com glutaraldeído foi observada em um microscópio óptico Standard 20 - Zeiss, utilizando uma lente objetiva com aumento de 100x para avaliação qualitativa. Uma pequena quantidade de cada amostra foi derretida em uma lâmina de vidro, com posterior sobreposição de uma lamínula para ser possível a visualização no microscópio.

\section{Teste de Fehling}

Para o teste de Fehling, 1 grama de cada suporte de imobilização, funcionalizado ou não, foi submetido a aquecimento em ebulição por $10 \mathrm{~min}$ com $5 \mathrm{~mL}$ de reagente de Fehling (Solução A e B na proporção 1:1). Após decorrido o tempo estipulado, foi observado se houve formação de precipitado no fundo do recipiente, bem como se houve alteração da coloração da parafina.

\section{Resultados e Discussão}

\section{Síntese do suporte de parafina com corante anilina e/ou carvão ativado}

Para todas as condições testadas de síntese do suporte (com corante e/ou carvão ativado), a parte superior do suporte apresentava-se porosa (face que ficou em contato com o ar) e, a parte inferior, irregular e lisa (face que ficou em contato com a água), resultado esse mais proeminente no suporte de corante + carvão. Esta tendência foi vinculada às características dos meios com que a parafina se encontra em contato durante a sua solidificação. O contato com a água, a qual produz uma barreira mais densa que o ar e, por encontra-se sob a parafina, tende a favorecer a compactação da parte inferior da mesma, conduzindo a uma face menos porosa, ou seja, mais lisa. 


\section{Funcionalização do suporte com glutaraldeído}

Após a funcionalização com glutaraldeído, as amostras foram analisadas qualitativamente em relação à presença de grupos reativos aldeídos na superfície do suporte mediante teste de Fehling, o qual conduz a formação de um precipitado de óxido cuproso $\left(\mathrm{Cu}_{2} \mathrm{O}\right)$, de coloração avermelhada, empregado como critério qualitativo da presença de glutaraldeído no suporte. Devido ao teste de Fehling requerer aquecimento em ebulição, a parafina funde, proporcionando a lixiviação de glutaraldeído para o meio, conduzido, em caso positivo, à formação de precipitado no fundo do frasco empregado nos testes.

Para a amostra em branco, ou seja, conduzida empregando parafina pura submetida ao mesmo processo de funcionalização com glutaraldeído, a parte superior permaneceu branca e não se constatou formação de precipitado no fundo do tubo de ensaio, indicando que não houve incorporação de glutaraldeído neste suporte.

Figura 2 - Resultado visual do teste de Fehling. (a) Pouco e (b) muito precipitado

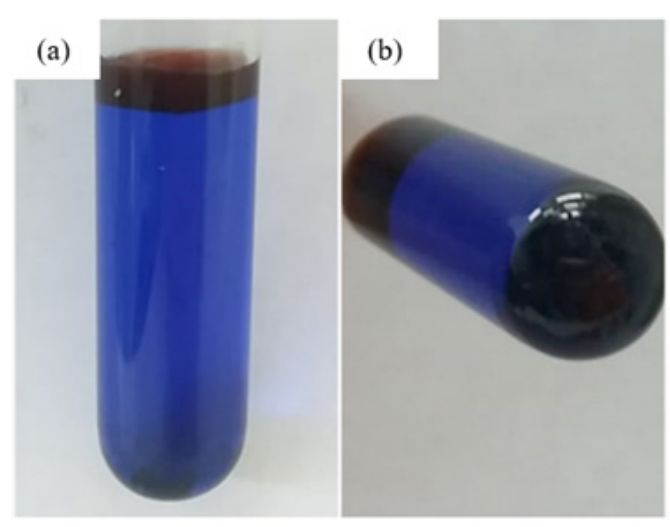

Diferentemente do ensaio em branco, os suportes contendo corante anilia e/ou carvão, após a funcionalização apresentaram uma mesma tendência, produzindo um precipitado avermelhado no fundo do recipiente (Figura 2), sugerindo a presença de glutaraldeído no meio, ou seja, que o processo de funcionalização foi eficiente.

Paralelamente, os diferentes suportes foram analisados em microscópio óptico, com aumento de 100x, resultando nas imagens apresentadas na Figura 3.

Figura 3 - Microscopias ópticas de estrutura dos suportes obtidos com aumento de 100x. Em (a) e (b) suporte de corante anilina sem e com glutaraldeído, respectivamente; em (c) e (d) suporte de carvão ativado sem e com glutaraldeído, respectivamente; e em (e) e (f) suporte de corante anilina + carvão ativado sem e com glutaraldeído, respectivamente

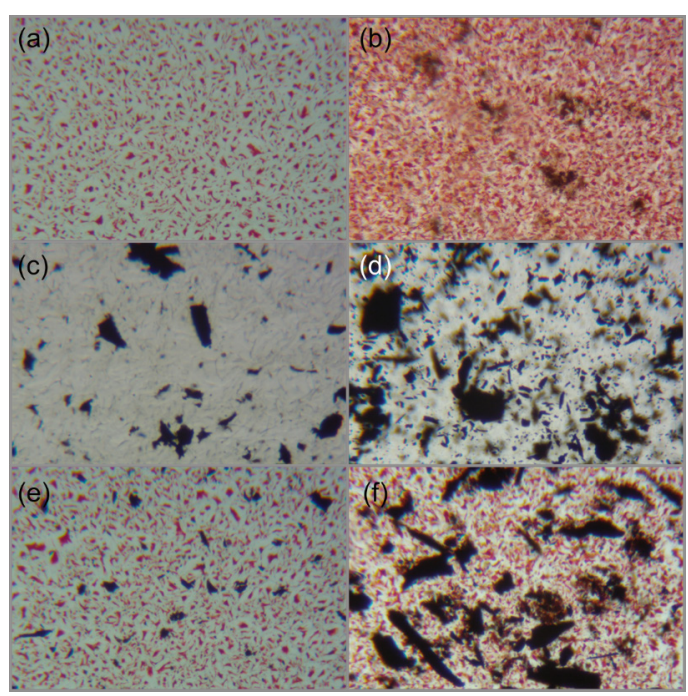

Podemos observar que tanto o corante quanto o carvão apresentaram uma distribuição homogênea no suporte (Figuras $3 \mathrm{a}, 3 \mathrm{c}$ e 3e). Após a funcionalização com glutaraldeído constatou-se o surgimento de manchas marrons em pontos do suporte, não observadas antes da funcionalização, o qual foi vinculado à presença de glutaraldeído no suporte. Cabe destacar que a parafina pura após ser submetida à etapa de funcionalização com glutaraldeído, não apresentou a presença destas manchas, indicando, novamente, que 
não houve impregnação/ligação do glutaraldeído com a parafina sem corante e/ou carvão (Figura 4).

Figura 4 - Microscopia óptica de estrutura da parafina pura após ensaio de funcionalização com glutaraldeído

\section{Imobilização enzimática}

\section{Estudo cinético}

O estudo cinético busca otimizar o tempo ótimo reacional necessário para a maximização da incorporação da enzima no suporte. Nos ensaios de imobilização acompanhou-se a diminuição da atividade do extrato enzimático, em contato, como suporte funcionalizado em função do tempo (Figura 5).

Figura 5 - Cinética de imobilização dos suportes funcionalizados com corante anilina e/ou carvão ativado

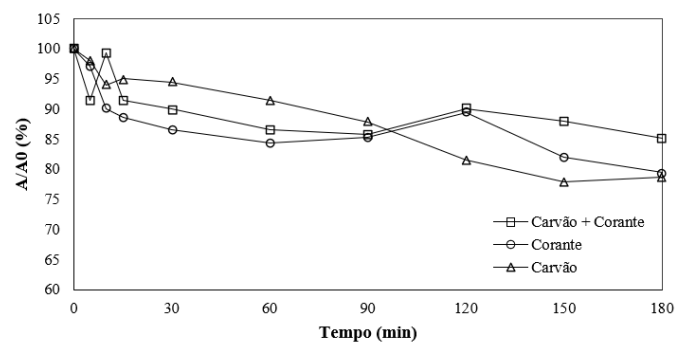

Os suportes funcionalizados contendo corante, de forma independente ou associa- do com carvão, foram os que apresentaram a melhor cinética reacional, conduzindo a uma diminuição significativa da atividade do extrato até os 60 minutos reacionais, permanecendo relativamente estável no restante do experimento, ou seja, até os 180 minutos empregados no ensaio. O suporte funcionalizado, contendo somente carvão, foi o que apresentou a cinética mais lenta, proporcionando uma diminuição gradativa da atividade no extrato até os 150 minutos $\mathrm{A}$ partir deste tempo de contato observa-se uma região de estabilidade.

Esta tendência observada foi vinculada com a composição do suporte, visto que a incorporação do corante anilina conduz a funcionalização do mesmo com grupos amino, os quais servem de pontos de ancoramento para o glutaraldeído, conduzindo a uma disponibilização mais efetiva dos mesmos para o ancoramento da enzima em relação ao carvão ativado.

No carvão ativado o glutaraldeído encontra-se adsorvido, preferencialmente no interior dos poros, onde a área de contato é maior, proporcionando para a enzima um efeito difusional que retarda o processo de incorporação, o que justifica a remoção gradativa observada para a atividade do extrato.

\section{Rendimento de imobilização}

Em se tratando de imobilização, um parâmetro importante a ser considerado é o rendimento de imobilização, o qual nos permite estipular a quantidade de enzima imobilizada, bem como se o processo foi favorável ou não para a enzima em questão.

O rendimento de imobilização para os suportes funcionalizados encontra-se apresentados na Tabela I. 
Tabela I - Rendimento (\%) dos suportes de parafina funcionalizados com corante anilina e/ou carvão ativado

\begin{tabular}{llll}
\hline & Carvão & Corante & Carvão + Corante \\
\hline Volume de extrato oferecido (mL) & 2,00 & 2,00 & 2,00 \\
Atividade do extrato (U/mL) & 4,00 & 4,00 & 4,00 \\
Atividade Total Oferecida (Uo) & 8,00 & 8,00 & 8,00 \\
Massa imobilizado (g) & 1,50 & 1,50 & 1,50 \\
Atividade do Imobilizado (U/g) & 2,66 & 2,61 & 2,62 \\
Atividade Total do Imobilizado (Ui) & 3,99 & 3,91 & 3,93 \\
Rendimento (\%) & 49,80 & 48,90 & 49,10 \\
\hline
\end{tabular}

De acordo com a Tabela I todos os suportes funcionalizados apresentaram valores similares para o rendimento de imobilização, o qual, considerando a atividade total presente no imobilizado em relação a oferecida, foi de aproximadamente de 50\%. Isto não significa que $50 \%$ da enzima presente no extrato foi incorporada, pois durante o processo de imobilização a atividade da enzima pode ser melhorada, por minimização de inibidores, exposição de novos sítios ativos por distorção da enzima, bem como facilidade do acesso de novos sítios ativos. Cabe destacar que a imobilização também pode proporcionar inativação da enzima, principalmente nos processos por ligação covalente, uma vez que a mesma ocorre nos grupos amino da enzima, os quais podem estar contribuindo para a atividade da mesma (GONÇALVES, 2018).

\section{Reciclos enzimáticos}

A reutilização do imobilizado pode ser estimada em função da variação da atividade dos mesmos após cada reciclo, a qual é apresentada na Figura 6.

De acordo com a Figura 6, todos os imobilizados apresentaram uma mesma tendência, mantendo sua atividade em aproximada- mente $100 \%$ durante os 20 ciclos testados, indicando que a enzima se encontra ancorada de forma eficiente ao suporte uma vez que não houve perda de atividade, a qual está normalmente relacionada com a lixiviação do suporte. Neste aspecto, pode-se observar que a enzima não está perdendo atividade.

Figura 6 - Número de reciclos enzimáticos avaliando os diferentes suportes testados

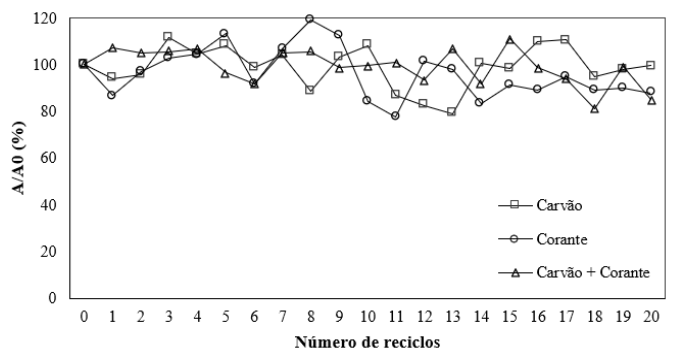

O resultado obtido é promissor em comparação ao encontrado na literatura para a urease imobilizada por incorporação, em pano de musselina impregnado com cera de parafina, a qual apresentou 8 reciclos com uma atividade residual final de $40 \%$ e mostrou perdas em todos os reciclos (PITHAWALA, MISHRA, BAHADUR, 2010). 
A enzima empregada nos testes foi uma

\section{Conclusão}

Pode ser verificado, no presente estudo, a eficiência dos aditivos de imobilização empregados na estrutura da parafina antes da funcionalização. Ambos (corante e/ou carvão) apresentaram resultados similares para as análises empregadas. Esse fato é importante uma vez que com a ausência dos mesmos, não é possível funcionalizar a parafina. pectinase, por sua característica desejável e fácil medida de atividade, com substrato não degradante do suporte escolhido (parafina). Foi possível verificar a eficiência do processo de imobilização frente ao rendimento $(\sim 50 \%)$ e reciclos (20 reciclos com $\sim 100 \%$ de estabilidade). A metodologia empregada é de baixo custo, rápida e de fácil reprodutibilidade e recuperação, características estas desejadas ao se escolher um suporte para imobilização enzimática.

\section{REFERÊNCIAS}

ADRIANO, W. S.; MENDONÇA, D. B.; RODRIGUES, D. S.; MAMMARELLA, E. J.; GIORDANO, R. L. C. Improving the properties of chitosan as support for the covalent multipoint immobilization of chymotrypsin. Biomacromolecules, v. 9, n. 8, p. 2170-2179, 2008.

ALMEIDA, C. M. S.; NASCIMENTO DE JESUS, J.; FERREIRA, R. D. M.; VARANDAS, V. S.; CAVALCANTE, P. A. W.; COÊLHO, D. F.; RODRIGUES, J. R. DA S.; SOUZA, R. R. DE; OLIVEIRA, T. S. DE. Immobilization of amylase using chitosan beads as support. Scientia Plena, v. 13, n. 11, p. 1-7, 2017.

BABAKI, M.; YOUSEFI, M.; HABIBI, Z.; BRASK, J.; MOHAMMADI, M. Preparation of highly reusable biocatalysts by immobilization of lipases on epoxy-functionalized silica for production of biodiesel from canola oil. Biochemical Engineering Journal, v. 101, p. 23-31, 2015.

BADGUJAR, K. C.; DHAKE, K. P.; BHANAGE, B. M. Immobilization of Candida cylindracea lipase on poly lactic acid, polyvinyl alcohol and chitosan based ternary blend film: Characterization, activity, stability and its application for N-a. Process Biochemistry, v. 48, n. 9, p. 1335-1347, 2013.

BARBOSA, O.; TORRES, R.; ORTIZ, C.; FERNANDEZ-LAFUENTE, R. Versatility of glutaraldehyde to immobilize lipases: Effect of the immobilization protocol on the properties of lipase B from Candida antarctica. Process Biochemistry, v. 47, n. 8, p. 1220-1227, 2012.

CHAUBEY, A.; PARSHAD, R.; TANEJA, S. C.; QAZI, G. N. Arthrobacter sp. lipase immobilization on magnetic sol-gel composite supports for enantioselectivity improvement. Process Biochemistry, v. 44, n. 2, p. 154-160, 2009.

CHEN, Z.; WANG, Y.; LIU, W.; WANG, J.; CHEN, H. A novel cross-linked enzyme aggregates (CLEAs) of papain and neutrase-production, partial characterization and application. International Journal of Biological Macromolecules, v. 95, p. 650-657, 2017.

FICANHA, A. M. M.; ANTUNES, A.; ORO, C. E. D.; DALLAGO, R. M.; MIGNONI, M. L. Immobilization of Candida antarctica B (CALB) in Silica Aerogel: Morphological Characteristics and Stability. Biointerface research in applied chemistry, v. 10, n. 6, p. 6744-6756, 2020.

FICANHA, A. M. M.; ANTUNES, A.; ORO, C. E. D.; FRANCESCHI, E.; DALLAGO, R. M.; MIGNONI, M. L. Immobilization of Lipase CALB in Organically Modified Silica. Biointerface research in applied chemistry, v. 11, n. 1, p. 7814-7825, 2021. 
GANGOLLI, S. The Dictionary of Substances and Their Effects. Royal Society of Chemistry, v. 6, p. 952, 1999.

GIRELLI, A. M.; SALVAGNI, L.; TAROLA, A. M. Use of lipase immobilized on celluse support for cleaning aged oil layers. Journal of the Brazilian Chemical Society, v. 23, n. 4, p. 585-592, 2012.

GONÇALVES, T. DOS S. Produção e funcionalização "in situ” de espuma de poliuretano sintetizado na presença de glutaraldeído. 2018. 128f. Dissertação (Mestrado em Engenharia de Alimentos) - URI Câmpus Erechim, Erechim, RS, 2018.

KAHWAJI, S.; JOHNSON, M. B.; KHEIRABADI, A. C.; GROULX, D.; WHITE, M. A. A comprehensive study of properties of paraffin phase change materials for solar thermal energy storage and thermal management applications. Energy, v. 162, p. 1169-1182, 2018.

MATEO, C.; PALOMO, J. M.; FERNANDEZ-LORENTE, G.; GUISAN, J. M.; FERNANDEZLAFUENTE, R. Improvement of enzyme activity, stability and selectivity via immobilization techniques. Enzyme and Microbial Technology, v. 40, n. 6, p. 1451-1463, 2007.

MILLER, G. L. Use of Dinitrosalicylic Acid Reagent for Determination of Reducing Sugar. Analytical Chemistry, v. 31, n. 3, p. 426-428, 1959.

PITHAWALA, K.; MISHRA, N.; BAHADUR, A. Immobilization of urease in alginate, paraffin and lac. Journal of the Serbian Chemical Society, v. 75, n. 2, p. 175-183, 2010.

RODRIGUES, D. S.; MENDES, A. A.; ADRIANO, W. S.; GONÇALVES, L. R. B.; GIORDANO, R. L. C. Multipoint covalent immobilization of microbial lipase on chitosan and agarose activated by different methods. Journal of Molecular Catalysis B: Enzymatic, v. 51, n. 3-4, p. 100-109, 2008. 
